\title{
Birth Defect and it's Impact in Neonatal Health : A Review
}

\author{
M A MANNAN ${ }^{1}$, SHARMIN AFROZE ${ }^{2}$, SANJOY KUMER DEY ${ }^{3}$, SADEKA CHOUDHURY MONI ${ }^{3}$, \\ MOHAMMAD KAMRUL HASSAN SHABUJ ${ }^{4}$, ISMAT JAHAN ${ }^{4}$, SHAHJADI NASREEN SULTANA ${ }^{7}$, \\ MOHAMMOD SHAHIDULLAH ${ }^{8}$
}

\begin{abstract}
Birth defects are one of the leading causes of neonatal mortality worldwide. Every year more than 8.14 million children are born with a serious birth defect. The risk factors predictive of birth defects in babies vary from country to country even from region to region. About $60 \%$ of the causes of birth defect in humans are still unknown. However, in about 25\% cases, the causes seem to be "multifactorial", indicating a complex interaction between genetic and environmental risk factors. Many studies have been conducted to determine the association of various risk factors with the incidence of birth defects. Most of them found significant association with maternal age, parity, consanguinity, poor nutrition, life style factors, low socioeconomic condition and many more. But still there is debate in certain issues like common type of birth defect, specific age of mother for having birth defect babies, role of drugs during pregnancy etc. With advancement of diagnostic tools, birth defects can be identified both prenatally and post- natally. This helps further in decision making and planning for both parents as well as physicians to provide accurate treatment in time. Major birth defect babies require intensive care and more hospitalization. Often multidisciplinary approach is essential for them. But till now birth defect cases are neglected in society. Increasing awareness about maternal care during pregnancy, educational programs on birth defect and the consequences of consanguineous marriages need to be highlighted to decrease the incidence of birth defect and their co-morbidities as well as mortality.
\end{abstract}

Key words: Birth defect, Congenital anomaly, Risk factors, Impact.

\section{Introduction:}

Birth defect is defined as structural or functional anomalies (e.g. metabolic disorders) that occur during intrauterine life and can be identified prenatally, at birth or later in life. ${ }^{1}$ Birth defects are important causes of childhood death, chronic illness and

1. Professor, Department of Neonatology, Bangabandhu Sheikh Mujib Medical University, Dhaka

2. Assistant Professor, Department of Neonatology, Dr. M. R Khan Shishu Hospital \& Institute of Child Health, Dhaka

3. Associate Professor, Department of Neonatology, Bangabandhu Sheikh Mujib Medical University, Dhaka

4. Assistant Professor, Department of Neonatology, Bangabandhu Sheikh Mujib Medical University (BSMMU), Shahbagh, Dhaka.

5. Medical Officer (on Deputation), Dhaka Mohanagar General Hospital, Dhaka South City Corporation, Dhaka

6. Professor \& Chairman, Department of Neonatology, Bangabandhu Sheikh Mujib Medical University, Dhaka.

Correspondence: Dr Sharmin Afroze, Assistant Professor, Department of Neonatology, Dr. M.R Khan Shishu Hospital \& Institute of Child Health, Dhaka, Bangladesh, Mobile:+88 01715579709, Email: mumu.sharmin8@gmail.com

Received: $26-10-2018$

Accepted: 16-03-2019 disability in many countries. It affects approximately 1 in 33 infants and is the fourth most common cause of neonatal mortality. ${ }^{2} \mathrm{~A}$ good knowledge on birth defect is essential to understand the aetiology behind this in order to reduce its hazardous impact on newborn.

Magnitude of Birth Defect: There has been a significant decline in infant and childhood mortality rates in most countries in the past two decades. This has primarily been due to extensive and successful use of immunization, control of diarrhoeal disorders, acute respiratory tract infections and improvement in health-care services through a focus on primary health care. ${ }^{3}$ As a consequence; birth defects have emerged as the major childhood health problem. An estimated 2, 76,000 babies die within 4 weeks of birth every year, worldwide, from congenital anomalies. ${ }^{1}$ Although the global incidence of birth defects is estimated at 3-7\%, the rate varies widely between countries. In Bangladesh, twelve percent of all 
neonatal deaths are due to birth defect which is alarming and prompt measures should be taken to address it timely. (Figure-1)

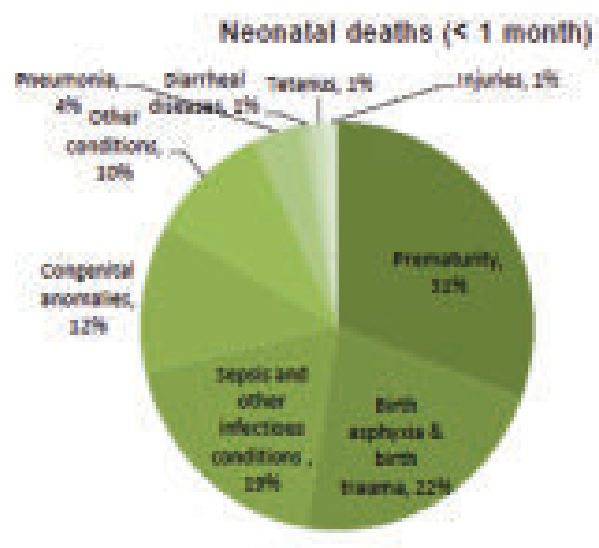

Fig.-1: Causes of Neonatal Deaths in Bangladesh [Source: CHERG/WHO/UNICEF for distribution of causes of neonatal death s (Published in Liu et al 2014)]

\section{Types of Birth defect:}

Birth defects or congenital anomalies are divided into major or minor according to severity. Major defects are structural abnormalities that have medical or cosmetic consequence. They may require surgical intervention like cleft palate and congenital heart disease such as Tetralogy of Fallot. Minor defects are anomalies with no medical or cosmetic significance. They may aid in diagnosis or recognition of a specific syndrome. Most of the minor abnormalities are limited to the head and neck region. Infants with three or more minor malformations are at high risk for having a major malformation (20-25\%) and /or a syndrome. ${ }^{4}$

Major and minor birth defects are often part of patterns like syndromes, associations, disruptions, deformations and developmental field defects. A syndrome consists of a group of anomalies that are associated due to single or similar etiologies, with known or unknown cause such as Down syndrome. Associations are clusters of malformations that occur together more frequently than occur sporadically, like VACTERL association (vertebral, anal, cardiac, tracheoesophageal fistula, renal and limb anomalies). Disruptions are extrinsic events that occur during normal development. Defect in amniotic bands can lead to amputation of digits or limbs. Deformations can occur when physical forces act upon previously formed structures such as uterine crowding or oligohydramnios that result in plagiocephaly or clubfeet. A developmental field defect consists of a group of anomalies resulting from defective development of a related group of cells (developmental field). In this condition, the involved embryonic regions are usually partially related but may not be contiguous in the infant like Holoprosencephaly, affecting the forebrain and face. ${ }^{4}$ It is also important to understand that these different types of birth defects may not be entirely mutually exclusive. ${ }^{5}$

Classification System for Birth Defects: The most popular classification system for birth defect till now is the ICD (international Classification of Disease) coding system. Most countries (117) use this system to report their health statistics. The International Statistical Classification of Diseases and Related Health Problems 10th Revision (ICD-10) has described Birth defects in chapter XVII (Q00-Q99) which is titled as 'Congenital malformations, deformations and chromosomal abnormalities' and excludes: inborn errors of metabolism (E70-E90). It has classified birth defects into several body systems along with chromosomal abnormalities and for each category there is a specific code. ${ }^{6}$

Patterns of Birth Defect: Regarding patterns of birth defect it may vary from country to country even from institution to institution depending on type of delivery taking place, type of patients coming from a particular region and availability of facility to detect birth defect cases. In the previous studies defects of the central nervous system were found predominantly in most of the countries. Recently due to advancement in diagnostic tools specially for bedside Echo availability, cardiovascular defects are leading birth defects. Francine $\mathrm{R}$ et al. and Singh $\mathrm{K}$ et al. found in their study that cardiovascular disease $(16.6 \%)$ was the highest followed by Musculoskeletal system, genitourinary system \& others. ${ }^{7,8}$

\section{Factors Responsible for Birth Defect:}

Around $40 \%$ to $60 \%$ of congenital anomalies are of unknown aetiology; $20 \%$ due to hereditary. Others are due to genetic mutations, chromosomal abnormalities and maternal illnesses, such as diabetes or infection, or use of anticonvulsant or other drugs (Figure-2). ${ }^{9}$ Many studies have been conducted to determine the association of various 


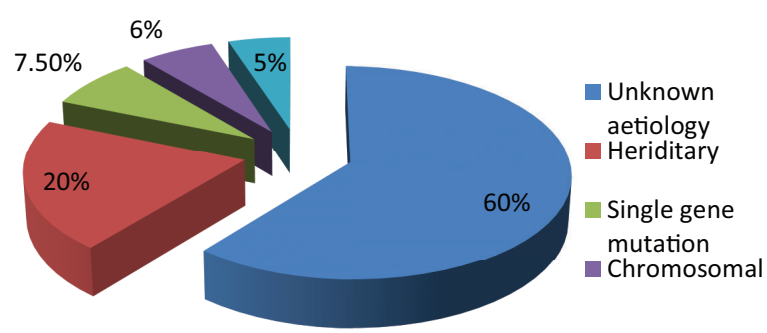

Fig.-2: Different Causes of Birth defect

risk factors with the incidence of birth defects. Most of the studies were done in cross sectional design. Few case control studies were also performed. Some studies were multi centered and included admitted newborns only where as others used all live born and still born babies.

Maternal Factors: There are several risk factors for birth defect worldwide which are more or less similar. In a country like Bangladesh some additional factors are high fertility rate, unplanned pregnancy, consanguineous marriage, non adherence to antenatal check up, poor maternal nutrition and high carrier rate for hemoglobinopathies.

Maternal Age: Association of maternal age with birth defect is considered as an important factor. Both younger and older maternal age may pose increased risks for birth defects. Limited data, however, exist on this association. Young maternal age and poor pregnancy outcome, including birth defects, is related to biologic factors such as mother's gynecological immaturity and nutritional status. ${ }^{10} \mathrm{~A}$ cross sectional study on birth defect in Mosul city by Taboo Z A in 2012 showed high incidence of birth defect in the young age group (median maternal age at diagnosis is 25 years). More consistent results have been published with respect to the association between young maternal age and gastroschisis. ${ }^{11-14}$

It is also widely recognized that older maternal age is strongly associated with chromosomal birth defects such as trisomies 13,18 , and $21 .{ }^{15}$ Several other studies have observed an association between older maternal age and non chromosomal birth defects like neural tube defects, cleft lip or palate, congenital inguinal hernia, and cardiac defects. ${ }^{11,16}$

Parity: Parity is a risk factor for birth defect. Previous studies have shown conflicting results in relation to parity as a variable. Aguiar et al. found a lower risk of neural tube defect in children of multiparous women ${ }^{17}$, where as Castilla et al. found a higher risk with greater parity (three or more children). ${ }^{18}$ Many studies observed that first birth is associated with an increased risk of selected birth defects like congenital hip dislocation and gastroschisis. Women having their first birth had significantly increased odds of having an infant with 24 of 65 categories of birth defects when compared to women having their second birth. ${ }^{19}$ This finding is similar with study done by Fatema et al. in Bangladesh.

Consanguinity: Consanguineous marriages are widely accepted and practiced globally. Bittles et al. estimated that 20-50 percent of all marriages in many regions of Asia and Africa are between first cousins. ${ }^{20}$ This doubles the risk of children being born with birth defects. ${ }^{21}$ It is proven by many authors like that consanguinity increase the risk of congenital anomalies ( $p$ value $<0.05){ }^{7}$

Poor Antenatal check up: Regular antenatal check up can help in early diagnosis of birth defect cases and termination of fetuses incompatible with life. But in many countries like Bangladesh, mothers do not come in regular check up. Fatema K et al (2011) and Mashuda $\mathrm{F}$ et al (2014) have found that poor and infrequent antenatal check up is a significant risk for birth defect. ${ }^{22}$ In Brazil, data shows increased odds of birth defects among newborns of mothers with few or no prenatal visits during the index gestation. ${ }^{23}$ Low socioeconomic and education status, hard to reach health facilities definitely have impact on this account.

Lack of Periconceptional Folic acid: Folic acid is essential for proper development of the neural tube, which becomes the spinal cord and the brain. Because the neural tube is completely developed by the third to fourth week of pregnancy, before most women realize they are pregnant, women need to be taking folic acid every day before they become

Table-I

Clinical Markers of high Risk Pregnancy 50

- Advanced maternal age

- Previous birth of a malformed fetus

- Family history of a malformed fetus

- Consanguinity

- Exposure to drugs/ radiation

- Maternal Diabetes mellitus

- Bad obstetric history 
Table -II

Antenatal screening tests for Birth Defects ${ }^{35}$

\begin{tabular}{lll}
\hline Trimester of pregnancy & Screening tests & Interpretation \\
\hline First (11-13 weeks) & $\begin{array}{l}\text { Maternal blood } \\
\text { • Human Chorionic- gonadotropin (hCG) } \\
\text { • Pregnancy associated plasma protein A } \\
\text { (PAPP-A). }\end{array}$ & $\begin{array}{l}\text { If theprotein levels are abnormally } \\
\text { high or low, thereCould be a } \\
\text { chromosomal disorder in the baby. }\end{array}$ \\
& Ultrasound & $\begin{array}{l}\text { If extra fluid behind the baby's neck- } \\
\text { chromosomal disorder }\end{array}$ \\
Second (15-20 weeks) & $\begin{array}{l}\text { Maternal blood (Triple screen" or } \\
\text { "quad screen") }\end{array}$ & \\
& $\begin{array}{l}\text { AFP (alphafetoprotein),hCG, estriol, } \\
\text { and inhibin-A. }\end{array}$ & $\begin{array}{l}\text { neural tube defects or } \\
\text { chromosomaldisorders such as } \\
\end{array}$ \\
& Anomaly scan & Down syndrome \\
& & All structural birth defect \\
\hline
\end{tabular}

Table-III

Screening and diagnostic tools used to detect Specific birth Defect ${ }^{51}$

\begin{tabular}{lll}
\hline Screen / Test & First Trimester & Second Trimester \\
\hline Screening for Down syndrome & $\begin{array}{l}\text { Nuchal Translucency (NT) } \\
\text { plus Maternal Serum Screening } \\
\text { ( } \beta \text { HCG/PAPP-A) 9+0 to 13+6 } \\
\text { weeks }\end{array}$ & $\begin{array}{l}\text { Maternal Serum Screening ( } \beta \text { HCG/uE3/ } \\
\text { AFP) 14+0 to 20+6 weeks }\end{array}$ \\
$\begin{array}{ll}\text { Screening for neural tube defects } \\
\text { Ultrasound from 12 weeks }\end{array}$ & $\begin{array}{l}\text { Maternal Serum Screening (AFP) 14+0 } \\
\text { to 20+6 weeks Ultrasound* }\end{array}$ \\
$\begin{array}{l}\text { Diagnostic testing tools for } \\
\text { chromosome abnormalities } \\
\text { and genetic disorders }\end{array}$ & $\begin{array}{l}\text { Chorionic Villus Sampling (CVS) } \\
\text { Amniocentesis After 15 weeks }\end{array}$ \\
\hline
\end{tabular}

* Ultrasound can detect neural tube defects at any stage of the second trimester, but the planned time for screening is typically at the routine morphology scan at 19-20 weeks

Abbreviations: $\boldsymbol{\beta}$ HCG, Beta human chorionic gonadotropin; PAPP-A, Pregnancy-associated plasma protein A; uE3, Unconjugated estriol; AFP, Alpha-fetoprotein.

Table-IV

Commonly used sampling procedures for antenatal diagnosis

\begin{tabular}{llll}
\hline Procedure & $\begin{array}{l}\text { CVC (Chorionic } \\
\text { Villus sampling) }\end{array}$ & Amniocentesis & Cordocentesis \\
& $9-12$ weeks (transcervical) & 16-18 weeks & $>18$ weeks \\
\hline Timing & $>12$ weeks (transabdominal) & & \\
& Fetalloss 3-5\%, feto-maternal & Fetal loss 0.5-1\%, feto-maternal & Fetal loss 1-5\% \\
Risk & hemorrhage and limb defects & hemorrhage and respiratory problems & \\
\hline
\end{tabular}


pregnant. Taking folic acid every day is also important because half of all pregnancies are un- planned. Some authors found lack of periconceptional folic acid supplementation in $63.5 \%$ mothers. ${ }^{22,24}$

Maternal disease: Many maternal diseases may occasionally lead to increased risk of birth defects such as hypertension, diabetes, febrile illness and hypothyroidism, but findings are not consistent.

Maternal Diabetes: Evidence suggests that infants of diabetic mothers have higher malformation rates. Multiple anomalies seem to be more common in diabetic than non-diabetic infants. Caudal regression has the strongest association with diabetes, occurring roughly 200 times more frequently in infants of diabetic mothers than in other infants. The teratogenic mechanism in diabetes is not clearly understood. ${ }^{25}$ But according to Castilla et al. diabetes causes embryopathy, resulting in malformations and spontaneous abortions. ${ }^{18,23}$

Maternal Hypertension: Hypertensive disorders and antihypertensive medication use in early pregnancy have both been suggested to directly affect fetal development through vascular disruption or other teratogenic mechanisms. ${ }^{26}$ A number of studies have explored whether the prevalence of specific birth defects may be increased by hypertension or its treatment. They found association of hypertension with specific birth defects, like congenital heart defects (CHDs), ${ }^{27-30}$ severe hypospadias, cleft lip with or without cleft palate, gastroschisis, and malformations of the central nervous system (CNS). ${ }^{31}$

Hypothyroidism: Babies born to women with abnormally functioning thyroid glands are at increased risk for heart, kidney and brain damage, as well as birth defects such as cleft lip and palate. A study was conducted at Johns Hopkins Hospital between 1994 and 1999 to see the incidence of birth defect among women having abnormal thyroid function. They found $18 \%$ had birth defects, ranging from cardiac, renal and central nervous system problems. But there are few similar studies in this aspect. ${ }^{32}$

Maternal infection: Infection during pregnancy is a major cause of birth defects accounting for $2 \%$ to $3 \%$.TORCH, includes Toxoplasmosis, Other (syphilis, varicella-zoster, parvovirus B19), Rubella, Cytomegalovirus (CMV), and Herpes infections, are some of the most common infections associated with birth defect like microcephaly, congenital heart disease and hydrocephalus. ${ }^{33}$ About 25 percent of babies whose mothers contract rubella during the first trimester of pregnancy are born with one or more birth defects, named as congenital rubella syndrome (CRS). Women who are infected with the rubella virus during the first 11 weeks of pregnancy have an up to 90 percent chance of delivering a baby with congenital rubella syndrome; whereas during the first 20 weeks, the rate drops to 20 percent. But the number of babies born with congenital rubella has decreased dramatically since the introduction of the rubella vaccine. ${ }^{34,35}$

Recently found that Zika virus that is passed from the mother to fetus can cause severe birth defects, including microcephaly and brain abnormalities. The risk of these birth defects is 20 times higher in women with Zika virus. ${ }^{36}$

Smoking and alcohol intake: Lifestyle factors have drawn increasing attention due to their capacity to influence the result of conception. Smoking has been associated with cleft lip, cleft palate and alcohol use with fetal alcohol syndrome. In developing countries like Bangladesh, cigarette smoking or alcoholism are not common for women, so evidence is not found. Also there may be a possibility that mothers of newborns with birth defects may attempt to protect themselves by denying or underestimating their risk behaviors during pregnancy, including alcohol consumption and cigarette smoking. But in developed countries it is one of the important risk factors. Even passive smoking of mother can bear the unborn baby at risk for problems. Hazem S M et al (2012) has found passive maternal smoking due to husband smoking is the second risk factor for birth defect (more than $50 \%$ of patients). ${ }^{37}$

Drugs: Only about $1 \%$ of all birth defects are caused by maternal drug use. ACE (angiotensin converting enzyme) inhibitors, angiotensin II antagonist, alcohol, cocaine, high doses of vitamin A, some anticonvulsant medications and some thyroid medications cause various congenital anomalies. ${ }^{38}$

Family history: A positive family history for birth defects has been associated with an increased risk of having another child with defect, with a recurrence rate ranging between 2 and $5 \%$ and $1 \%$ for neural tube defects and Down syndrome respectively. 22,39 
Low socio-economic condition: It is observed that mothers who belong to low socio economic background have increased risk of birth defect babies due to poor nutritional status. In this group, ignorance and lack of education is also common which leads to in-frequent antenatal check up and delayed diagnosis. Nazer J, López CJ, Castilla EE (2001) found in their study that birth defects were more among infants born at public maternity hospital than private hospital. ${ }^{40}$

On the other hand, the lower prevalence of birth defect in private maternity hospitals may reflect behavior by women with higher socioeconomic status (similar to those from developed countries), due either to greater self-care and care for the infant or termination of the pregnancy following intrauterine diagnosis of a fetal malformation. ${ }^{41}$

\section{Impact of Birth Defect:}

Many studies stated that newborns with malformation have an increased frequency of low birth weight, prematurity, and anoxia. It emphasizes the fact that these children require high level of care at birth, thus justifying the need for reference units for such cases. ${ }^{23}$

Prematurity and low birth weight (LBW): Birth defects contribute to the occurrence of preterm birth and LBW. Francine R (2014) found in their study that congenital malformation was significantly associated with relatively low weight of the baby $(p=0.027)$. Some other authors also found the same findings. ${ }^{7,42}$

In relation to birth weight, according to reports in the literature, children with neural tube defects show an increased proportion of low birth weight due to the malformations themselves, as in anencephaly, or as the result of their effect on fetal growth. ${ }^{17,44,46}$

Perinatal asphyxia: Major malformations leads to intrauterine hypoxic state which ultimately turns into perinatal asphyxia. Many studies found low 5 minute APGAR score in birth defect babies like Nhoncanse S C et al (2014) and Francine R (2014). 7,45

Morbidity and mortality: Birth defects have gained increasing importance due to both high mortality and morbidity. Children with adverse outcomes require intensive care in the first days of life and in some cases admission to an intensive care unit, thereby increasing the probability of diagnosing an anomal. Serious birth defects can be lethal. According to
Chung \& Myrianthopoulos (1987), the odds of a child with a congenital malformation dying were 3.85 in the neonatal period and 2.81 in the post-neonatal period. ${ }^{49}$ Costa showed the same magnitude in determining perinatal death $(A O R=8.47)$ as did low birth weight $(A O R=8.78) .{ }^{23}$

\section{Long Term Impact:}

For those birth defect babies, who survive, these disorders can cause lifelong mental, physical, auditory or visual disability. ${ }^{47-49}$ Developmental disabilities include:

Nervous system or brain problems - learning disabilities, mental retardation, behavioural disorders, speech or language difficulties, convulsions, and movement trouble.

Sensory problems - blindness, cataracts and other visual problems, and varying degrees of hearing loss including deafness.

Metabolic disorders - phenylketonuria (PKU) and hypothyroidism.

Degenerative disorders - conditions that might not be obvious at birth, but develop intellectual delay that gets worse progressively. Examples are: X-linked adreno-leukodystrophy. ${ }^{3}$

\section{Diagnosis:}

Birth defects can be diagnosed during pregnancy or after the baby is born, depending on the specific type of birth defect.

\section{Prenatal screening:}

During pregnancy, high risk pregnant women (Table1) are usually offered these screening tests to check for birth defects or other problems for the woman or her baby. ${ }^{50}$ These include maternal blood tests and ultrasound (Table-2, 3). ${ }^{35}$ Ultrasound screening is a very reliable tool for assessing birth defects. In a major study on $5,00,000$ cases about $11,000(2.2 \%)$ were found to be malformed fetus with a range of sensitivity from 14 to $85 \%$ (mean $45.5 \%$ ). In another study on 1,70,000 pregnant women, 4000 malformed fetus were detected with a sensitivity of $61 \% .{ }^{51}$

\section{Other tests:}

If the result of a screening test is abnormal, diagnostic tests are done to determine if birth defects or other possible problems with the baby are present. These diagnostic tests are also offered to women with higher 
risk pregnancies. These are invasive procedures which bear a potential risk for fetus (Table-4).

\section{Postnatal diagnosis:}

Certain birth defects might not be diagnosed until after the baby is born. Major birth defects are seen easily but for minor defects we have to examine the baby thoroughly. Besides this, investigations like Xray, Ultrasonography and blood tests can help us to reach a confirm diagnosis and to find out associations. It also helps physicians to manage the baby accordingly.

\section{Treatment:}

Treatment of birth defect babies often requires multidisciplinary approach. Team members include neonatologist, pediatric surgeon, pediatric neurologist, pediatrician, nurses, physiotherapist, dietician, social worker and some other people. But proper counseling about the condition and its consequences is a major challenge for the physicians. Treatment consists of general supportive care and specific treatment like surgery. In a study in Bangladesh, authors found among admitted birth defect babies $69.2 \%$ underwent surgery and $51 \%$ operated cases died. ${ }^{52}$ Timely diagnosis and early intervention along with adequate life support can save many birth defect babies.

\section{Prevention:}

Though not all birth defects can be avoided, prenatal care and awareness of past or current conditions can help with prevention.

\section{Prenatal Care:}

Pre-conception counseling: it is a meeting with a health-care professional of a woman before attempting to become pregnant. It generally includes a preconception risk assessment for any potential complications of pregnancy as well as modifications of risk factors, such as counseling on smoking cessation, alcohol reduction and medications that may compromise fetal development. ${ }^{53}$

Ensuring vaccination: Vaccines are an important part of planning and having a healthy pregnancy. Chickenpox (varicella) and rubella infections during pregnancy can cause serious birth defects. If a woman plan to conceive, she should get a varicella or MMR vaccine, at least one month before getting pregnant.

\section{Care during pregnancy:}

Folic acid and vitamin intake: Taking a daily prenatal vitamin that includes at least 400 micrograms of folic acid can prevent a variety of birth defects. Efforts should be made to ensure that more women use folic acid during the peri-conceptional period, as the use of folic acid supplement has been linked by several authors to a reduced occurrence of some congenital anomalies. ${ }^{35}$

Control of diabetes before and during pregnancy: Poor control of diabetes during pregnancy increases the chances for birth defects and other problems for the baby. It can also cause serious complications for the woman. Proper control of diabetes mellitus before and during pregnancy can help prevent birth defects and other poor outcomes. ${ }^{54}$

\section{Prevention of infection:}

TORCH: Pregnant women should wash hands thoroughly after contact with children's saliva or diapers, avoid kissing children younger than 6 years old on the cheek or mouth and avoid sharing food and drink with young children to prevent CMV transmission. Those who are infected with the rubella virus during pregnancy must be closely monitored.

Zika virus infection can be prevented by avoiding insect bite by using insect repellant, wearing a longsleeved shirt and long pants when outside and avoiding travel to areas with Zika virus.

Awareness of past or current conditions: If mother previously had a pregnancy with a birth defect, it's important to find out the most likely causes because it can help physician to plan preventive measures for next pregnancy.

\section{After Birth:}

Early detection and treatment of birth defects: can prevent stillbirth or physical and intellectual disabilities. Surgery can also be used to treat many birth defects, including cleft lip and palate and spina bifida, sometimes even before a child is born. The idea behind prenatal surgery is to limit long-term damage through early intervention. Prenatal heart and renal-tract defects are often treated surgically while the child is still in the womb, providing decompression and early correction for a better developmental prognosis. Although gene therapy is also a possible option for treating certain genetic defects, it is not yet used on a wide scale. ${ }^{35}$ 


\section{Planning measures:}

Birth defects are far more common than people realize. Many studies contribute to the planning of measures in maternal and child health, with a focus on resource allocation for prevention of congenital malformations, both primary (health education), secondary (adequate prenatal care with broad coverage), and tertiary (organization of referral networks). ${ }^{23}$

\section{Conclusion:}

Birth defects are not rare. In fact, the increasing contribution of birth defect in neonatal mortality is alarming. Risk factors vary from country to country but some common causes need urgent attention like improvement of nutritional status of teen age population along with periconceptional folic acid supplementation and ensuring regular antenatal check up. Besides these, national policy and awareness program on birth defect can reduce incidence as well as impact of it.

Disclosure: The author reports no conflicts of interest in this work.

\section{Reference:}

1. World health organization Report Update. April 2015

2. World Health Organization Report 2012. Birth defects in South - East Asia, A Public Health Challenge: Situation Analysis. WHO report.

3. World Health Organization Report 2013. Birth defects in South - East Asia, A Public Health Challenge: Situation Analysis. WHO report.

4. Bacino CA. Common Genetic problems in the Newborn. In: Cloherty JP, Eichenwald EC, Hansen AR, Stark AR, editors. Manual of Neonatal Care, Seventh edition. New Delhi. Wolters Kluwer;2012.P.111-112.

5. Gomella TL, Cunningham DM, Eyal FG, editors.Neonatology: Management, Procedures, On-call Problems, Diseases and Drugs, Seventh edition. New York. Mc Graw Hill. Lange; 2013.P.600.

6. World Health Organization Report Updates. June 2016.

7. Francine R, Pascale $\mathrm{S}$, Aline $\mathrm{H}$. Congenital Anomalies: Prevalence and Risk Factors. Universal Journal of Public Health. 2014; 2 (2): 58-63.
8. Singh K, Krishnamurthy K, Greaves C, Kandamaran L, Nielsen A L, Kumar. Major Congenital Malformations in Barbados: The Prevalence, the Pattern, and the Resulting Morbidity and Mortality. Obstetrics and Gynecology 2014; published online, http:// dx.doi.org/10.1155.

9. Nelson K, Holmes LB. Malformations due to presumed spontaneous mutations in newborn infant's. N Engl J Med. 1989; 320:19-23.

10. Gill SK, Broussard C, Devine O, Green RF, Rasmussen SA, Reefhuis J. Association between Maternal Age and Birth Defects of Unknown Etiology - United States, 1997-2007. Birth Defects Research (Part A): Clinical and Molecular Teratology; 2012.

11. Reefhuis J, Honein MA. Maternal age and nonchromosomal birth defects, Atlanta-1968-2000: teenager or thirty-something, who is at risk? Birth Defects Res A Clin Mol Teratol. 2004; 70:572-9.

12. Benjamin BG, Ethen MK, Van Hook CL. Gastroschisis prevalence in Texas 1999-2003. Birth Defects Res A Clin Mol Teratol. 2010; 88:178-185

13. Loane M, Dolk H, Morris JK. Maternal agespecific risk of non-chromosomal anomalies. EUROCAT Working Group. BJOG. 2009; 116:1111-1119.

14. Chabra S, Gleason CA, Seidel K, Williams MA. Rising prevalence of gastroschisis in Washington State. J Toxicol Environ Health. 2011; 74:336- 345.

15. Hagen A, Entezami M, Gasiorek-Wiens A et al. The impact of first trimester screening and early fetal anomaly scan on invasive testing rates in women with advanced maternal age. Ultraschall Med. 2011; 32:302-306.

16. Khoshnood B, Bouvier-Colle $\mathrm{MH}$, Leridon $\mathrm{H}$, Blondel B. Impact of advanced maternal age on fecundity and women's and children's health. J Gynecol Obstet Biol Reprod. 2008; 37:733747.

17. Aguiar MJB, Campos AS, Aguiar RALP, Lana AMA, Magalhães RL, Babeto LT. Defeitos de fechamento do tubo neural e fatores associados 
em recémnascidos vivos e natimortos. J Pediatr.2003; 79:129-34.

18. Castilla EE, Lopez-Camelo JS, Paz JE, Orioli IM. Prevención primaria de los defectos congénitos. Rio de Janeiro: Editora Fiocruz. 1996.

19. McNeese ML, Selwyn BJ, Duong H, Canfield $M$, Waller DK. The association between maternal parity and birth defects. Birth Defects Res a Clin Mol Teratol. 2015;103(2): 144-56.

20. Bittles $\mathrm{AH}$, Mason WM, Greene $J$ et al. Reproductive behavior and health in consanguineous marriages.Science. 1991; 252:789-94.

21. Stoltenberg C, Magnus P, Lie RT, Daltveit AK, Irgens LM. Birth Defects and Parental Consanguinity in Norway. Am J Epidemiol. 1997; 145: 5

22. Mashuda F, Zuechner AZ, Chalya PL, Kidneya $B R$, Manyama M. Pattern and factors associated with congenital anomalies among young infants admitted at Bugando medical centre, Mwanza, Tanzania. Biomed central. 2014; 195:1-7.

23. Costa C M S, Gama S N G, Leal MC. Congenital malformations in Rio de Janerio, Brazil: prevalence and associated factors. Cad. Saude Publica, Rio de Janerio. 2006; 22: 2423 - 31.

24. Raza M Z, Sheikh A, Ahmed S, Ali S, Naqvi SMA. Risk factors associated with birth defects at a tertiary care center in Pakistan. Italian Journal of Pediatrics. 2012. 38:68.

25. Mills JL. Malformations in Infants of Diabetic Mothers. Birth Defects Res A Clin Mol Teratol. 2010; 88(10): 769-778

26. Gelder V, Bennekom CV, Louik C, Werler M, Roeleveld N, Mitchellb A. Maternal hypertensive disorders, antihypertensive medication use, and the risk of birth defects: a case-control study. Hum Reprod Update. 2010; 16:378-94.

27 Li DK, Yang C, Andrade S, Tavares V, Ferber JR. Maternal exposure to angiotensin converting enzyme inhibitors in the first trimester and risk of malformations in offspring: a retrospective cohort study. BMJ. 2011; 343:d5931.
28. Cooper WO, Hernandez-Diaz S, Arbogast PG, Dudley JA, Dyer S, Gideon PS, et al. Major congenital malformations after first trimester exposure to ACE inhibitors. N Engl J Med. 2006; 354:2443-51.

29. Caton AR, Bell EM, Druschel CM, Werler MM, Lin AE, Browne ML, et al. Antihypertensive medication use during pregnancy and the risk of cardiovascular malformations. Hypertension. 2009; 54:63-70.

30. Lennest AR, Otterblad OP, Kcall EB. Maternal use of antihypertensive drugs in early pregnancy and delivery outcome, notably the presence of congenital heart defects in the infants. Eur J Clin Pharmacol. 2009; 65:615-25.

31. Caton AR, Bell EM, Druschel CM, Werler MM, Mitchell AA, Browne ML, et al. Maternal hypertension, antihypertensive medication use, and the risk of severe hypospadias. Birth Defects Res A Clin Mol Teratol. 2008; 82: 34-40.

32. Bouchez C. Thyroid Disorders Again Linked to Birth Defects. Health Day Report, January 2002.

33. Stegmann BJ, Carey JC. TORCH Infections. Toxoplasmosis, Other (syphilis, varicella-zoster, parvovirus B19), Rubella, Cytomegalovirus (CMV), and Herpes infections. Curr Womens Health rep. 2002; 2(4):253-8.

34. Bar-Oz B, Levichek Z, Moretti ME, Mah C, Andreou S, Koren G. Pregnancy outcome following rubella vaccination: a prospective controlled study. Am J Med Genet A. 2004; 130(1):52-54.

35. Nasrin B, Mahmood S, Shamsunnahar PA, Islam S, Naher BS, Huq M A. Birth Defect: An Overview. Journal of Paediatric Surgeons of Bangladesh. 2013; 4(2):58-66.

36. Saleh N. 5 Infections That Cause Birth Defects. Very Well family report. 2018.

37. Hazem SEM, Hassan S K, Alaa EMI, Rami M. Epidemiology of birth defects in Women's health university center Assiut-Egypt: an observational cross sectional study. Am J Sci.2012; 8: 777781. 
38. Bottom of Form Sofia FW, Schjott J. Risk perception regarding drug use in pregnancy. American Journal of Obstetrics and Gynecology. 2017;216(4): 375-378.

39. Koumi E, Banna A, Lebda I. Pattern of congenital anomalies in newborn: a hospitalbased study. Pediatr Rep. 2013; 5(1):0-3.

40. Nazer J, López CJ, Castilla EE. ECLAMC: Estudio de 30 años de vigilancia epidemiológica de defectos de tubo neural en Chile y en Latinoamérica. Rev Med Chile. 2011; 129:5319.

41. Liu S, Joseph KS, Wen SW, Kramer MS, Marcoux S, Ohlsson A, et al. Secular Trends in Congenital Anomaly-Related Fetal and Infant Mortality in Canada, 1985-1996. Am J Med Genet. 2001; 104:7-13.

42. Honein MA, Kirby RS, Meyer RE, Xing J, Skerrette NI, Yuskiv N, Marengo L, Petrini JR, Davidoff MJ, Mai CT, Druschel CM, VinerBrown S, Sever LE. The association between major birth defects and preterm birth', Matern Child Health J. 2009; 13(2):164-75.

43. Dolan SM, Gross SJ, Merkatz IR, Faber V, Sullivan LM, Malone FD et al. The contribution of birth defects to preterm birth and low birth weight. Obstet Gynecol. 2007;110(2):318-24.

44. Pardo RA, Nazer J, Cifuentes L. Prevalencia al nacimiento de malformaciones congénitas y de menor peso de nacimiento en hijos de madres adolescents. Rev Med Chile. 2003;131:116572.

45. Nhoncanse G C, Germano C M R, Avo L R, Melo DG. Maternal and perinatal aspects of birth defects: a case-control study. Rev Paul Pediatr. 2014; 32(1): 24-31.
46. Chung CS, Myrianthopoulos NC. Congenital anomalies: mortality and morbidity, burden and classification. Am J Medical Genetics. 1987; 27:505-23.

47. Potter JD, McMichael AJ, Hetzel BS. Iodization and thyroid status in relation to stillbirths and congenital anomalies. International Journal of Epidemiology. 1979; 8:137-144.

48. Robertson SE, Featherstone DA, Gacic-Dobo M, Hersh BS. Rubella and congenital rubella syndrome: global update. Rev Panam Salud Publica. 2003;14(5): 306-315.

49. Walker DG, Walker GJ. Prevention of congenital syphilis-time for action. Bull World Health Organ. 2004; 82:401.

50. Malhotra N, Malhotra J, Tomar S, Bora NM, JP Rao, Bora R, Malhotra K. Ultrasonography and Birth Defect. Donald School Journal of Ultrasound in Obstetrics and Gynaecology. 2013; 7 (2): 149-159.

51. Prenatal Screening for Congenital Anomalies in South Australia 2011.South Australian Birth Defects Register, Women's and Children's Hospital Adelaide, South Australia, September 2014.

52. Banu T, Chowdhury TK, Das S K, Chowdhury M Z, Hoque M M, Rahman MAM. Birth Defects: A Hospital Based Study in Chittagong, Bangladesh. Chattagram Maa-O-Shishu Hospital Medical College Journal. 2014; 13:3.

53. Letitia W, D'Angelo Z, Morrow H. Associations between preconception counseling and maternal behaviors before and during pregnancy. Matern Child Health J. 2012; 16: 1854-1861.

54. Buchanan TA, Xiang AH. Gestational diabetes mellitus. Journal of Clinical Investigation. 2005; 115: 485-491. 